\title{
Psychosocial Effects of Fractured Anterior Teeth among Rural Children
}

${ }^{1}$ Ramesh Venkatesan, ${ }^{2}$ Mohan Naveen, ${ }^{3}$ Ravi Teja, ${ }^{4}$ Shankar Paulindraraj, ${ }^{5}$ Sai K Vallabhaneni, ${ }^{6}$ Selva B Arumugam

\begin{abstract}
Aim: The aim of the study is to determine how rural children view children with visible incisor fracture.

Materials and methods: Class 7 (aged 11-12 years) and class 10 (aged 14-15 years) schoolchildren (the participants) were invited to make a social judgment about the color photograph of two children (the subjects). Participants were randomly allocated either (i) pictures of children without incisor fracture or (ii) pictures of the same children whose photographs had been digitally modified to visible incisor fracture. Using a childcentered questionnaire, participants rated subjects using a fourpoint Likert scale for three negative and six positive attributes. Total attribute scores were tested for significant differences, according to whether the subject had visible incisor fracture or not, using multivariate analysis of variance $(p<0.05)$.
\end{abstract}

Results: Both class 7 and 10 children rated subjects with visible incisor fracture more negatively than the subjects without incisor fracture. Female participants of class 10 have rated the male subject with incisor fracture significantly negatively $(p<0.01)$ than male subject without incisor fracture.

Keywords: Attribute, Fracture, Psychosocial, Trauma.

How to cite this article: Venkatesan R, Naveen M, Teja R, Paulindraraj S, Vallabhaneni SK, Arumugam SB. Psychosocial Effects of Fractured Anterior Teeth among Rural Children. Int J Clin Pediatr Dent 2016;9(2):128-130.

Source of support: Nil

Conflict of interest: None

1,3-6 Senior Lecturer, ${ }^{2}$ Pediatric Dentist
1,6 Department of Pediatric and Preventive Dentistry, Indira
Gandhi Institute of Dental Sciences, Sri Balaji Vidyapeeth
University, Puducherry, India
${ }^{2}$ Private Practice, Villupuram, Tamil Nadu, India
${ }^{3}$ Department of Oral Pathology and Microbiology, SIBAR
Institute of Dental Sciences, Guntur, Andhra Pradesh, India
${ }^{4}$ Department of Pediatric and Preventive Dentistry, Madha
Dental College and Hospital, Chennai, Tamil Nadu, India
${ }^{5}$ Department of Pediatric and Preventive Dentistry, SIBAR
Institute of Dental Sciences, Guntur, Andhra Pradesh, India

Corresponding Author: Ramesh Venkatesan, Senior Lecturer, Department of Pediatric and Preventive Dentistry, Indira Gandhi Institute of Dental Sciences, Sri Balaji Vidyapeeth University, Puducherry, India, Phone: +919944454064, e-mail: sandsi.ramesh@gmail.com

\section{INTRODUCTION}

Increase in concern toward dental appearance can be observed among schoolchildren. ${ }^{1,2}$ Schoolchildren can be unkind and hostile to those with visible differences, with teasing and bullying being everyday occurrences. ${ }^{3}$ A total of $75 \%$ of children cited teasing or bullying about their appearances as causing considerable distress. ${ }^{4}$ This may not pertain only to children in urban areas. When self-esteem of children in rural towns was assessed, it was found that rural children's self-perceptions are not distinctly different from urban and suburban children. ${ }^{5}$ Teeth holds a greater share of attention in facial esthetics, and a dental appearance that deviates from acceptable norms may even negatively affect an individual. ${ }^{6}$ Thus, the aim of our study is to determine the psychosocial effects of fractured anteriors among rural children and to explore the effect of age and gender on character perception by rural children.

\section{MATERIALS AND METHODS}

\section{The Photographs}

Full face color photographs (Figs 1A and B) of a boy and a girl, aged between 11 and 15 years, were taken after obtaining informed consent from the parents. Copies of the same photographic images were digitally modified so that it appeared like the incisor was either fractured or fractured and discolored.

\section{The Questionnaire}

The questionnaires used in this study were originally developed by Rodd et $\mathrm{al}^{7}$ and were found to have good internal consistency. The questionnaire included nine descriptors (six positive and three negative attributes) within three different domains: Social competence, psychosocial adjustment, and intellectual competence. The positive descriptors included were clever, kind, honest, confident, careful, and helpful and the negative descriptors were rude, stupid, and naughty. Since English is not the mother tongue of the participants, the descriptor words were translated in regional language-Tamil.

Study participants included all class 7 and class 10 pupils at a secondary school at Annamalai Nagar, Chidambaram, India. The school administrator randomly 

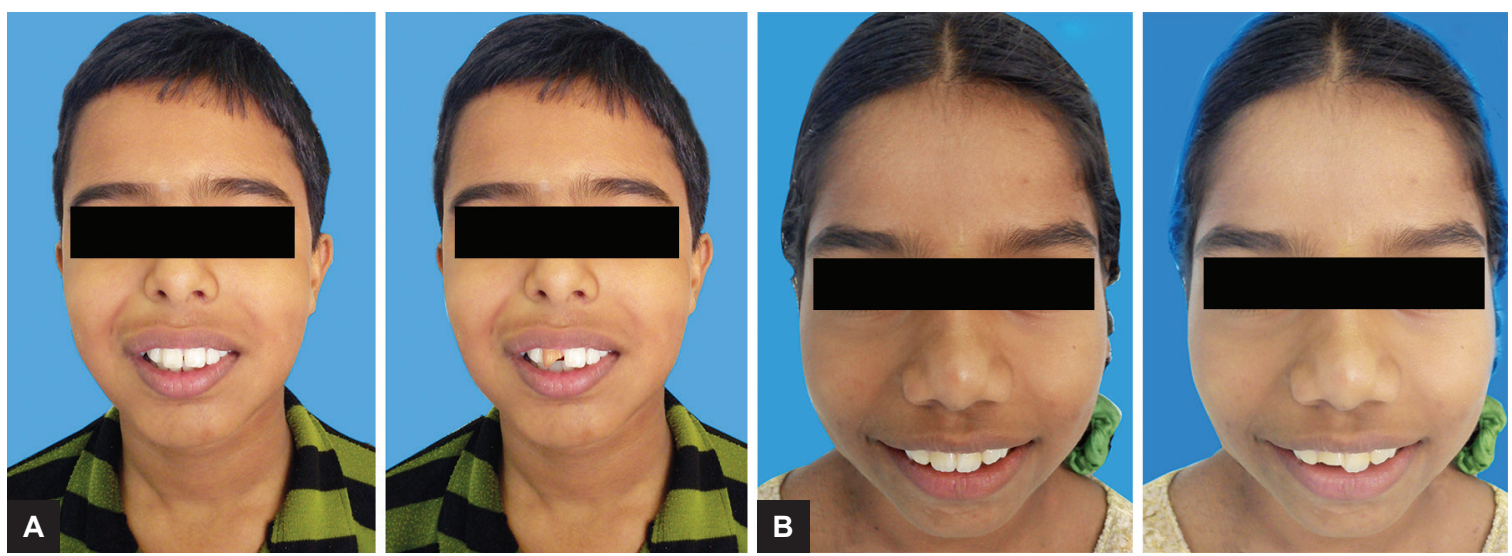

Figs $1 A$ and $B$ : Full face photographs of the two subjects in this study: $(A)$ without incisor fracture and $(B)$ with fractured incisor (digitally modified)

allocated the questionnaires and photographs to each class, so that half of the class 7 and 10 groups received the trauma photographs and the remaining classes received the nontrauma photographs. They were asked to rate each child for the nine social attributes. A four=point Likert scale was used to record responses, ranging from "strongly agree," "agree," and "disagree" to "strongly disagree." The participants were not told that the study was dentally related. Participants were not allowed to confer during completion of their questionnaire.

\section{Data Analysis}

The total attribute score was calculated by summing the response codes. The positive attributes namely clever, kind, honest, confident, careful, and helpful were coded as "strongly agree" $=4$; "agree" $=3$; "disagree" $=2$; "strongly disagree" $=1$. The negative attributes of rude, stupid, and naughty had the scoring reversed. Thus, a high score (maximum of 36) would correlate with positively judged subject and a low score (minimum of 9) would correlate with a negatively viewed subject. The use of parametric tests has been reported as appropriate for analysis of similarly obtained social attribute scales in previous studies. ${ }^{8,9}$ The two dependent variables were the mean total attribute score for each of the paired photographs. The fixed factors were gender of the participant (male or female), the school class (class 7 or 10), and incisor status (presence or absence of visible incisor fracture). Significant results from multivariate analysis of variance were examined using descriptive statistics and post hoc multiple comparisons. The significance level was set at $\mathrm{p}<0.05$.

\section{RESULTS}

The participants of the study were class 7 and 10 students of a rural school. The total number of participants was 199 , of whom 111 (55.8\%) students belonged to class 7 and $88(44.2 \%)$ students were from class 10 . Number of male participants in class 7 was 79 and 32 were female. And there were 53 male and 35 female participants in class 10 .

Table 1 provides the mean attribute scores for the subject of each photograph (with or without incisor fracture) according to the age and gender of the participant. Both class 7 and 10 participants rated subject with incisor fracture more negatively than subject without incisor fracture for both male and female subjects. Female participants of class 10 have rated the male subject with incisor fracture significantly negatively $(\mathrm{p}<0.01)$ than male subject without incisor fracture. Male participants in total have rated female subject with incisor fracture more negatively $(p=0.01)$ than the female participants. None of the remaining main effects or interactions was statistically significant.

\section{DISCUSSION}

The aim of this study was to determine whether children with visible incisor fracture are viewed more negatively

Table 1: Mean (standard deviation) attribution scores for children with and without visible incisor trauma according to the age and gender of the participant

\begin{tabular}{lllllll}
\hline Photographic subject & $\begin{array}{l}\text { Class 7 total } \\
(n=11)\end{array}$ & $\begin{array}{l}\text { Class } 7 \text { boys } \\
(n=79)\end{array}$ & $\begin{array}{l}\text { Class } 7 \text { girls } \\
(n=32)\end{array}$ & $\begin{array}{l}\text { Class 10 total } \\
(n=88)\end{array}$ & $\begin{array}{l}\text { Class 10 boys } \\
(n=53)\end{array}$ & $\begin{array}{l}\text { Class 10 girls } \\
(n=35)\end{array}$ \\
\hline Subject 1 (male) with incisor \# & $25.79(3.59)$ & $25.40(3.89)$ & $25.70(4.09)$ & $25.45(4.48)$ & $25.00(4.84)$ & $24.83(4.03)$ \\
Subject 1 (male) without incisor \# & $26.78(4.18)$ & $27.27(4.22)$ & $26.75(2.71)$ & $25.96(3.52)$ & $25.29(4.03)$ & $27.00(2.40)$ \\
Subject 2 (female) with incisor \# & $24.08(5.11)$ & $22.11(3.34)$ & $25.50(6.57)$ & $24.96(5.09)$ & $23.53(4.93)$ & $27.33(4.66)$ \\
Subject 2 (female) without incisor \# & $24.55(4.22)$ & $23.58(4.30)$ & $27.00(4.73)$ & $26.25(4.22)$ & $24.83(4.69)$ & $28.44(2.13)$ \\
\hline
\end{tabular}


than those with intact incisors by rural children. There is considerable evidence to suggest that teeth hold a greater share of attention in the face. According to Newton et $\mathrm{al}_{1}{ }^{8}$ in the absence of other information, the judgments an individual makes concerning the personal characteristics of others are influenced by dental appearance. Feng et $\mathrm{al}^{9}$ reported that subjects with less dental disease were judged to be better adjusted and more intellectually competent.

In the present study, there was no marked difference in the evaluation of any of the subjects according to age. Though not statistically significant, both boys and girls of class 7 rated both the subjects with incisor fracture more negatively than subjects without incisor fracture. The mean attribute score given by class 10 boys toward both male and female subjects with incisor fracture was consistently negative than subjects without incisor fracture, but were not statistically significant, whereas the mean attribute score given by class 10 girls toward the male subject with incisor fracture was significantly negative than male subject without incisor fracture. In a similar study, Rodd et $\mathrm{al}^{7}$ found that children aged 11 to 12 years would make negative social judgment on the basis of poor dental appearance. Kershaw et $\mathrm{al}^{10}$ reported that decayed dental appearance led to more negative judgments over the four personality categories (social competence, intellectual ability, psychological adjustment, and relationship satisfaction). Whitened teeth led to more positive appraisals.

Since there is remarkable decline in prevalence and severity of dental caries, traumatic dental injury has become the most serious dental public health problem in children. ${ }^{11}$ Many studies state that prevalence of traumatic dental injuries ranges from 4 to $19.5 \%$, of which the percentage of traumatized teeth that had undergone treatment is very low (3.37\%). ${ }^{12-14}$ This low percentage is due to low level of awareness among the parents of the children in the rural areas. ${ }^{14}$

\section{CONCLUSION}

From the results of this study, it is observed that both 11 to 12-year-old children and 14- to 15-year-old children attribute negative personality characteristics to other children with incisor fracture. It is evident that social judgments made by rural children toward peeraged children with incisor fracture may have adverse psychosocial effects. So efforts should be made to increase knowledge among the rural children and their parents about the fracture to anterior teeth and its psychosocial effects.

\section{REFERENCES}

1. Shaw WC, Lewis HG, Robertson NRE. Perception of malocclusion. Br Dent J 1975 Mar 18;138(6):211-216.

2. Gosney MB. An investigation into some of the factors influencing the desire for orthodontic treatment. Br J Orthod 1986 Apr;13(2):87-94.

3. Shaw WC, Meek SC, Jones DS. Nicknames, teasing, harassment and the salience of dental features among school children. Br J Orthod 1980 Apr;7(2):75-80.

4. Lovergrove E, Rumsey N. Ignoring it doesn't make it stop: adolescents, appearance, and bullying. Cleft Palate Craniofac J 2005 Jan;42(1):33-44.

5. Yang RK, Fetsch RJ. The self-esteem of rural children. J Res Rural Educ 2007 Jun 15;22(5):1-7.

6. Jenny J, Proshek JM. Visibility and prestige of occupations and the importance of dental appearance. J Can Dent Assoc 1986 Dec;52(12):987-989.

7. Rodd HD, Barker C, Baker SR, Marshman Z, Robinson G. Social judgements made by children in relation to visible incisor trauma. Dent Traumatol 2010 Feb;26(1):2-8.

8. Newton JT, Prabhu N, Robinson PG. The impact of dental appearance on the appraisal of personal characteristics. Int J Prosthodont 2003 Jul-Aug;16(4):429-434.

9. Feng XP, Newton JT, Robinson PG. The impact of dental appearance on perceptions of personal characteristics among Chinese people in the United Kingdom. Int Dent J 2001 Aug;51(4):282-286.

10. Kershaw S, Newton JT, Williams DM. The influence of tooth colour on the perceptions of personal characteristics among female dental patients: comparisons of unmodified, decayed and 'whitened' teeth. Br Dent J 2008 Mar;204(5):256-257.

11. Petersson HG, Bratthall D. The caries decline: a review of reviews. Eur J Oral Sci 1996 Aug;104(4 Pt 2):436-443.

12. Tulley WJ. Importance of mouth guards. Br Dent J 1966 May 3;120(9):502.

13. Garcia-Godoy F, Sanchez R, Sanchez JR. Traumatic dental injuries in a sample of Dominican school children. Community Dent Oral Epidemiol 1981 Aug;9(4):193-197.

14. Govindarajan M, Reddy VN, Ramalingam K, Durai KS, Rao PA, Prabhu A. Prevalence of traumatic dental injuries to the anterior teeth among three to thirteen-year-old children of Tamilnadu. Contemp Clin Dent 2012 Apr;3(2):164-167. 